\title{
Assessment of nutritional status of hospitalized patients including their food intake and evaluation of food waste, its causes and consequences in some selected Tehran hospitals: a cross-sectional study protocol
}

\section{Razieh Anari}

National Nutrition and Food Technology Research Institute https://orcid.org/0000-0001-6296-3521

Maryam Amini

National Nutrition and Food Technology Research Institute

Bahareh Nikooyeh

National Nutrition and Food Technology Research Institute

Delaralm Ghodsi

National Nutrition and Food Technology Research Institute

Parisa Torabi

Iran Ministry of Health and Medical Education

Tirang R Neyestani ( $\square$ neytr@yahoo.com )

National Nutrition and Food Technology Research Institute https://orcid.org/0000-0002-0953-2594

\section{Study protocol}

Keywords: economic burden, food waste, hospital, malnutrition, nutrition, nutritional status, qualitative study, study protocol

Posted Date: August 3rd, 2020

DOI: https://doi.org/10.21203/rs.3.rs-45878/v1

License: (c) (1) This work is licensed under a Creative Commons Attribution 4.0 International License. Read Full License 


\section{Abstract}

Background: Hospitalization may seriously affect patients' nutritional status and may occasionally be accompanied by malnutrition development or aggravation. Food intake is often altered during hospitalization, which is tightly connected to malnutrition. On the other hand, a huge amount of plate food wasted by patients, in addition to its health consequences, has enormous economic and environmental expenses for governments and societies. This investigation aims firstly to assess nutritional status of the patients hospitalized in general wards and secondly to evaluate the quantity and financial burden of patients' food waste along with its possible nutritional outcomes.

Methods: A cross-sectional study is performed on 171 adult inpatients with eligibility criteria from medical and surgical wards of three general hospitals in Tehran. Nutritional status of patients is evaluated through the following methods: 1. Assessment of malnutrition using subjective criteria (Mini Nutritional Assessment and Subjective Global Assessment tools); 2. Assessment of protein status using determination of serum albumin, pre-albumin and total protein; and 3. Assessment of certain micronutrient status notably vitamins $A$ and $D$ using serum retinol and 25-hydroxycalciferol assay. Also, oxidative stress and inflammatory status are evaluated using examination of serum $\beta$-carotene, total antioxidant capacity, malondialdehyde and highly sensitive C-reactive protein. Anthropometric and demographic data are collected and energy and protein intakes are extracted from a 24 -hour food recall. Plate food wastes for selected patients are weighed in breakfast, lunch and snacks for one day. Then, economic cost of food waste is calculated for each meal, patient and ward. Finally, the possible reasons for wasting food in these hospitals will be evaluated through conducting a qualitative study.

Discussion: Findings of this study will provide appropriate data regarding health and economic burden of food waste in studied hospitals. These data are especially useful to healthcare authorities and policy makers for planning efficient solutions to decrease food waste and to improve patients' nutritional status.

\section{Contributions To The Literature:}

- Inadequate food intake (IFI) in hospitalized patients is a contributing factor in hospital food waste. IFI has also a pivotal role in creating or exacerbating hospital malnutrition. · Hospital food waste and its economic burden has been less studies in Iran. - In this study, IFI and resulting food waste and its potential implication in the patients' clinical status and economic burden will be put together in a picture and evaluated simultaneously for the first time.

\section{Background}

Hospitalized patients are mostly (67-94\%) dependent on hospital's food to supply their nutritional requirements $(1,2)$. Patients with insufficient food intake are more susceptible to nutritional deficiency (3), which is prevalently observed in hospitalized patients (4) and can cause or exaggerate malnutrition (5, 
$6)$. Studies reported that a noticeable proportion of hospitalized patients ( 40\%) suffer from malnutrition globally, including both developed $(20-46 \%)$ and developing countries $(\sim 50 \%)(4,7,8)$. For instance, a recent Canadian prospective cohort revealed that around $40 \%$ of admitted patients had some sort of malnutrition and longer hospital stays (9). This figure was reported between 30 to $63.1 \%$ in Iranians hospitals (10-12). Moreover, a comprehensive study in 20 general Iranian hospitals revealed that almost one out of four patients suffered from malnutrition (13). Under-nutrition can also influence medical treatment and recovery from the disease $(4,14)$, risk of infection $(15)$ and even risk of death $(6,16)$. Malnourished patients also have longer hospital stay and more likelihood of readmission $(16,17)$, that could increase hospital costs up to $308.9 \%$ (17).

Adequate nutrition is associated with a better clinical outcome in hospitalized patients (18). However, approximately $30 \%$ of patients' food remains intact during hospitalization (4). This measure varies from country to country. For example, a study in Portugal demonstrated that on average $35 \%$ of served food is wasted by patients in a day (equaled to $953 \mathrm{gram}$ ) (19). Investigations in UK hospitals also showed that patients leave $14 \%$ of their meals during three consecutive days (20) and as high as $40 \%$ of served food during 28 days (21). Based on previous studies in Iranian hospitals, the plate food waste ranges from 14 to $47 \%$ of total wasted materials in hospitals $(12,22-24)$.

On the other hand, wasted foods may have some adverse environmental impacts by emitting $\mathrm{CO}_{2}$. The European Union estimates an average emission of at least 1.9 tons of $\mathrm{CO}_{2}$ per ton of wasted food arising from both food chain (e.g. production, processing, transportation, storage and preparation) and after wasting processes (25), leading to exacerbation of global warming (26).

Beside clinical and environmental aspects, food waste is also important regarding economic impacts on governments and health systems (27). The approximate cost of a prepared food in hospitals is at least $€$ 2 (28), depending on country and culinary factors such as culture. For instance, food waste annually contributes to 35.5 million Euros of health expenses in Portuguese hospitals (19) and 139,655 GBP in UK hospitals (21).

Many factors including malnutrition, disease situation, food delivery system, food palatability or its quality may alter patients' food intake. For example, the rate of food satisfaction in hospitalized patients in Tehran metropolitan was only $27 \%$ (29), which could exaggerate food waste. The reasons for incomplete food intake and resulting food waste are not necessarily similar among different patients and wards. Previous studies reported the highest amount of food waste in medical, gastroenterology and surgical wards $(10,19)$. Thus, the underlying factors for food waste should be precisely and locally identified.

In spite of the importance and extent of food waste, there is a lack of sufficient data regarding clinical and economical dimensions of food waste in Iranian hospitals. Therefore, this study aims to assess nutritional status of patients hospitalized in medical and surgical wards of three general hospitals in Tehran metropolitan and also to determine the quantity and cost of food waste in those hospitals. We will also determine the main causes of food discard by patients to propose the appropriate solutions to reduce it. 


\section{Methods/design}

Study design: A cross-sectional study will be carried out in medical and surgical wards of three general hospitals in Tehran, Iran, including Shohada-ye-Tajrish, Shahid Modarres, and Emam-Hossein, all belong to Shahid Beheshti University of Medical Sciences. This study aims to: (i) assess malnutrition and nutritional intake of patients, (ii) measure plate food waste and estimate its cost, (iii) identify the reasons for wasting food by patients (Figure 1).

Calculation of sample size: Considering the effect size of 0.25 and the power of $90 \%$, the sample size will be 171 patients, as calculated using G* Power software (30).

Subjects: We will consequently enroll adult inpatients hospitalized in medical and surgical wards of three general hospitals in the study until fulfillment of the sample size. Following criteria will be used for enrolment:

Inclusion criteria: Hospitalization in medical or surgical ward, age $\geq 19$ years, consumption of hospital food, i.e. food prepared in hospital's kitchen and distributed by serving staff, and patient's satisfaction to participate in the study.

Non-Inclusion criteria: Pregnancy, unconsciousness, or disability to eat by themselves.

Exclusion criteria: Diet transition to liquid or soft diet, enteral or parenteral feeding or NPO (nil per oral), transferring to another wards (except medical and surgical) or Intensive Care Unit (ICU), discharge from hospital or death, lack of plate return to the kitchen for any reason.

Ethical considerations: The Ethics Committee of National Nutrition and Food Technology Research Institute (NNFTRI) approved the study protocol (ethical code: IR.SBMU.NNFTRI.REC.1398.073; Approval Date: 2020-01-05). Due to the cross-sectional and observational nature of the study, we will implement no intervention and only current malnutrition status, food intake and reasons to waste food will be assessed. Before initiation, patients will declare their consent to enter the study through signing a written testimonial.

Data collection and variables: Data will be collected in several parts:

1. Demographic data: A socio-demographic questionnaire, including age, sex, education, marital status, cause of hospitalization, disease history, length of stay, smoking status and current drugs and supplements use will be fulfilled for each participant.

2. Anthropometric measures: A trained nutritionist will take anthropometric measures. Patients' weights will be measured using a calibrated digital scale with the accuracy of 100 gram (g) (Seca, model 840, Maximum: $140 \mathrm{~kg}$, Hamburg, Germany). In case of movement restriction (due to heavy surgeries, fractions, paralysis, etc.), weights will be recorded as self-reported by the patient. For patients with edema, the physician will determine the weight. Heights will be measured in standing position with minimum cloths and the accuracy of 0.1 centimeter $(\mathrm{cm})$ (Seca, Hamburg, Germany). If direct measurement is not 
feasible because of the patient's condition, indirect methods will be applied to estimate heights, either using ulna length (31) or preferably using knee height by a non-flexible tape-measure $(32,33)$. To estimate height using ulna length, the distance between the point of elbow (olecranon process) and the midpoint of prominent bone of the wrist (styloid process), possibly from left side, will be measured and rounded to the nearest $0.5 \mathrm{~cm}$ and height will be estimated using the standard method (31). Knee height will also be measured in supine lying position using a tape meter, by holding both knee and ankle at 90 -degree angles $(32,33)$ and height will be calculated using the following formulas:

Heights for males $(\mathrm{cm}): 64.19-(0.04 \times$ age $)+(2.02 \times$ knee height $)$

Heights for females $(\mathbf{c m}): 84.88-(0.24 \times$ age $)+(1.83 \times$ knee height $)$

3. Quantity of plate food waste: Food waste will be measured during two main meals (breakfast and lunch) and snacks (in the morning and evening). Food ingredients will be extracted from the hospital's food guide and validated by asking the chef or food preparing staff. A trained nutritionist will record the average portion size by weighing at least two sample dishes in each meal using a portable digital scale with the accuracy of $1 \mathrm{~g}$. Foods served in trays, dishes or disposable containers will be distributed among the due wards, i.e. medical and surgical wards, through hospital's food delivery system and leftovers will be returned to the weighing zone. Then, total amount of plate food waste will be measured and calculated per studied patient, meal (breakfast, lunch, snacks) and ward as the following:

$$
\mathrm{WP}=\frac{1}{n}\left(\sum_{i=1}^{n} \frac{\sum_{j=1}^{3} \mathbf{W F}_{i j}}{\sum_{j=1}^{3} \mathbf{F P}_{i j}}\right) \times 100
$$

WP: percent of daily wasted food per patient

$\mathrm{n}$ : total number of the studied patients

i: refers to the specific daily measurement for each patient

WF: weight of daily wasted food for each patient in each meal (gr)

FP: average weight of the food portion in each meal in the day of measurement (gr)

j: refers to the specific meal including $1=$ breakfast, $2=$ snacks, and $3=$ lunch

$$
\mathrm{WM}=\frac{1}{n}\left(\sum_{i=1}^{n} \frac{\mathrm{WF}_{i j}}{\mathrm{FP}_{i j}}\right) \times 100, \mathrm{j}=1,2,3
$$


WM: percent of daily wasted food per meal

$$
\mathrm{WW}=\frac{1}{d}\left[\sum_{i=1}^{d}\left(\mathrm{WP} \times \mathrm{n}_{d}\right)\right] * 100
$$

WW: percent of daily wasted food per ward

$\mathbf{n}_{\mathbf{d}}$ : total number of eligible patients in each ward in the day of measurement

d: total number of the measurement days

4. Cost of food waste: A nutritionist will extract food ingredient by asking the chef. After measuring the portion size, the total price of a usual portion will be estimated by asking food provider who routinely buys raw materials for the kitchen. This will not include procedure expenses, like energy or employees' salary cost. Cost of food waste will be calculated and reported per studied patient, meal (breakfast, lunch, snacks) and ward using the following equations:

\section{$\mid C W P=W P \times T C M$ \\ $\operatorname{TCM}=\frac{1}{\mathrm{~d}} \sum_{k=1}^{d}\left(\sum_{j=1}^{3} \mathrm{CM}_{\mathrm{kj}}\right), \mathrm{j}=1,2,3$}

CWP: cost of wasted food per patient in the day of measurement (Rial)

TCM: average total cost of all meals in a day (Rial)

CM: cost of food portion in each meal in the day of measurement (Rial)

$\mathbf{k}$ : refer to the day of measurement

$$
\begin{aligned}
& C W M=W_{j} \times C E M_{j}, j=1,2,3 \\
& C E M=\frac{1}{d}\left(\sum_{k=1}^{d} C M_{k j}\right), j=1,2,3
\end{aligned}
$$

CWM: cost of wasted food per meal in the day of measurement (Rial)

CEM: average cost of each meal in a day (Rial) 


\section{$\mathbf{C W W}=\mathbf{C W P} \times \mathbf{N}$}

CWW: cost of daily wasted food per ward (Rial)

$\mathrm{N}$ : average daily number of eligible patients in each ward during the study period

All costs of food waste will be reported in the national currency and will be finally converted to US dollar using the average exchange rate during the study period.

5. Nutritional value of wasted food: The amount of wasted food will be entered into Nutritionist IV software (First Data Bank Inc., San Bruno, CA, 1997) to extract energy, protein and micronutrients content (vitamin $A$ and $D$ ) of wasted food for each patient.

6. Nutritional intake and requirement: The mean daily energy and protein intakes will be extracted from a 24-hour food recall using Nutritionist IV software (First Data Bank Inc., San Bruno, CA, 1997) modified for Iranians foods' ingredients. The mean daily energy and protein intake will be reported for medical and surgical wards of studied hospitals. Resting metabolic rate (RMR) will be calculated for each patient according to age, weight and sex using equation developed for Iranians for patients 19-59 years old (34) or Mifflin equation for those $\geq 60$ years old (35) (Table 1). Finally, total energy expenditure (TEE) will be calculated considering injury factors (IF) and activity factors (AF) (36) (Table 2) as:

TEE $=$ RMR $\times$ IF $\times \mathbf{A F}$

7. Malnutrition assessment: We will assess subjective and objective malnutrition for each eligible patient as the following:

7.1 Subjective malnutrition: Subjective malnutrition will be evaluated using subjective tools: subjective global assessment (SGA) tool for adults 19-65 years old (37) and mini-nutritional assessment (MNA) tool for adults $\geq 65$ years old (38).

7.2 Objective malnutrition: Protein malnutrition will be evaluated by measuring serum albumin, prealbumin (PAB) and total protein using standard methods. If the concentrations of all three serum proteins are low, it will signify protein malnutrition (39). Micronutrient malnutrition will be assessed by assessing vitamins $A$ and $D$ status using serum retinol and 25-hydroxycalciferol [25(OH)D] determination, respectively.

\section{Biochemical analyses:}

Blood sample preparation: The day after measuring food waste, $10 \mathrm{~mL}$ venous blood sample will be drawn from patients. The samples will be immediately sent to the Laboratory of Nutrition Research, NNFTRI, in a cold box and serums will be separated by centrifuging at $800 \mathrm{~g}$ for $20 \mathrm{~min}$ at room temperature and will be stored at $-70^{\circ} \mathrm{C}$ until the day of biochemical examinations. 
The following biochemical tests will be employed to assess selected micronutrient status (vitamins A and D), protein malnutrition (albumin, PAB and total protein), anti-oxidative defense (total antioxidant capacity [TAC], malondialdehyde [MDA] and $\beta$-Carotene), and inflammatory status of the patients (highly sensitive $C$ reactive protein [hs-CRP]):

8.1 Serum retinol:, To assess vitamin A status, serum retinol will be measured using high performance liquid chromatography (HPLC) as originally described (40) with some minor modifications (41). In this study, serum concentrations $0.35-0.70 \mu \mathrm{mol} / \mathrm{L}(10-20 \mu \mathrm{g} / \mathrm{dL})$ will be considered as marginal vitamin $A$ deficiency, $<0.35 \mu \mathrm{mol} / \mathrm{L}(10 \mu \mathrm{g} / \mathrm{dL})$ as vitamin A deficiency, $>1.05 \mu \mathrm{mol} / \mathrm{L}(30 \mu \mathrm{g} / \mathrm{dL})$ as adequate status and $>3.49 \mu \mathrm{mol} / \mathrm{L}(100 \mu \mathrm{g} / \mathrm{dL})$ as hypervitaminosis A (42-44).

8.2 Serum $\beta$-Carotene: Serum concentrations of $\beta$-carotene will be assayed using HPLC (45). Actually, serum retinol and $\beta$-carotene will be determined simultaneously.

8.3 Serum 25(OH)D: Vitamin D status will be determined by measuring circulating 25(OH)D concentrations using enzyme immunoassay (EIA) method (Padtan Gostar Isar ${ }^{\circledR}$, Tehran, Iran). In this study, serum 25(OH)D concentrations $>50 \mathrm{nmol}(20 \mathrm{ng} / \mathrm{mL})$ will be considered as sufficiency, 27.5-50 $\mathrm{nmol}(11-20 \mathrm{ng} / \mathrm{mL})$ as insufficiency and $<27.5 \mathrm{noml} / \mathrm{L}(11 \mathrm{ng} / \mathrm{mL})$ as deficiency $(46)$.

8.4 Serum MDA: Serum MDA, as a biomarker of oxidative stress, will be assessed by measuring thiobarbituric acid reactive substances (TBARS), as described elsewhere $(47,48)$.

8.5 Serum TAC: TAC will be evaluated using 2,2-azinobis (3-ethylbenzothiazoline-6-sulfonate) (ABTS) reagent and bovine serum albumin as standard (49).

8.6 Serum hs-CRP: It will be measured using EIA (Pars Azmoon, Tehran, Iran). In this study, serum hs-CRP will be interpreted as following (50): < $3.0 \mathrm{mg} / \mathrm{L}$ : normal; 3-10 mg/L: minor elevation; 10 to $100 \mathrm{mg} / \mathrm{L}$ : moderate elevation; > $100 \mathrm{mg} / \mathrm{L}$ : marked elevation; and > $500 \mathrm{mg} / \mathrm{L}$ : severe elevation.

8.7 Serum albumin: We will measure serum albumin using the specific commercial kit (Pars Azmun, Iran). Concentrations 5-5.0 g/dL will be considered normal (51).

8.8 Serum PAB: Serum pre-albumin will be measured through turbidimetric immunoassay method using commercial kit (Zellbio, Germany). Concentrations between 15 and $35 \mathrm{mg} / \mathrm{dL}$ will be considered normal (52).

8.9 Serum total protein: Serum total protein will be measured using a specific commercial kit (Pars Azmun, Iran). The normal range for total protein is between 6.0 to $8.4 \mathrm{~g} / \mathrm{dL}$ (51).

\section{Qualitative study:}

9.1 Participants: To collect data regarding possible reasons for wasting food, we will conduct a qualitative study with nurses, nutritionists, food staff (i.e. chef, chef assistant, and delivery staff), food providers, hospital managers and patients hospitalized in medical and surgical wards of the studied hospitals. 
9.2 Methods: The qualitative study includes several individual "In-depth" interviews. The interviews will be guided by a "Topic Guide" (Table 3). After the clarification of the objectives and procedure of the qualitative study for the participants, they will be allowed to read and sign the written consent. The topic Guide will be developed based on objectives of the study and target groups. It will be a "semi-structured" questionnaire which means the questions will not be asked necessarily in a specific order. There will be six target groups including nurses, dieticians, food providers, patients. hospital managers and food staff for whom the topic guide will be prepared. It will contain some main and probing questions about reasons for wasting plate-food by patients. Depending on the question, some complementary questions will be asked. Clear words and neutral sentences will be used to make it understandable for interviewees, but to not affect their responses. The interviews will be continued until "data saturation" in which no novel responses will be given. At this point, the researcher will stop the sampling (53). Each interview will last 30 to 60 minutes and will be held in a suitable calm place in the hospitals. The research team will consist of a facilitator and at least one note-taker. At the beginning of the interview, the facilitator will introduce herself and clarify the aim and procedure of the study. All the participants' answers and cues (body languages) in addition to date and place of the interview will be recorded by the note-taker(s). To avoid missing any details, the interviews will be recorded by a voice-recorder simultaneously by the participants' permission. A member of the research team qualified in qualitative studies as observer will observe some of the interviews by random. She will assess 'quality assurance' through auditing the processes of interviewing, coding, analysis and interpretation of data to control reliability and validity of data. To ensure that the interviewer has an accurate understanding of the interviewee's responses, she will restate her perception of their answers during and at the end of the interview and will ask them to correct her perception if necessary (member check). Furthermore, by collecting answers from different sources, e.g. from dissimilar participant groups, the validity of the data will be assured (triangulation). During coding stage, a part of the interviews (e.g. $20-30 \%$ of total) will be separately coded by another member of the research team. The percentage of agreement will be calculated and reported for inter and intra raters, as well. Before starting the fieldwork, some pilot interviews will be conducted in some target groups to resolveany inadequacies.

9.3 Qualitative data analysis: In this study, we will collect, analyze and classify data, simultaneously. The approach of the study will be "content analysis" (54). To begin the analysis, all notes will be sent to MAXQDA software (Version 10, VERBI Software Consult. Sozialforschung. GmbH, Berlin, Germany). To explore emerging themes and subthemes the notes will be read many times carefully by the research team, followed by organizing (coding) data based on the main objectives of the study. Then, frequency of each theme will be determined and categories will be developed based on the most frequent themes. Finally, the research team will discuss about emerging the themes and core categories. To calculate the percentage of agreements (between and within coders), kappa test will be used.

10. Statistical analyses: Quantitative and qualitative data of food waste and nutritional status will be analyzed using SPSS software (version 21, SPSS Inc., Chicago, IL, USA). Quantitative data for variables like quantity and cost of food waste will be reported as mean \pm standard deviation (SD), and qualitative data, like malnutrition status or micronutrients deficiency, will be expressed as percent or proportion. Shapiro-Wilk test will be used for evaluating the normality of data distribution. Biochemical results will be 
compared among different malnutrition categories, wards and hospitals using one-way analysis of variance (ANOVA) or the equivalent non-parametric test. Finally, data analysis by linear logistic regression will propose a model using P-value less than 0.05 as significant.

Data of the qualitative study on reasons for wasting foods will be analyzed using MAXQDA software (Version 10, VERBI Software Consult. Sozialforschung. GmbH, Berlin, Germany) and reported as themes and subthemes and categories. Finally, the main influencing factors affecting hospital food waste will be explored and reported.

\section{Discussion}

The primary objective of this study is to evaluate nutritional status, quantity and cost of food wasted by hospitalized patients in medical and surgical wards. The secondary objective is to identify the main causes for wasting foods by patients to propose solutions to reduce that.

This study has several strengths: A variety of biomarkers, regarding protein malnutrition, micronutrient deficiency, oxidative stress and inflammation will be measured. Also, malnutrition will be assessed in both subjective (using MNA and SGA tools) and objective (using biomarkers) forms. Some studies suggested an association between some serum biomarkers, like albumin, PAB and retinol with patient's nutritional status or recent dietary intake (55-57). Moreover, the amount and cost of food waste and its possible effects on patients' nutritional status (due to inadequate intake) will be evaluated simultaneously which will provide a reliable data about the current situation in hospitals for health authorities and policy makers. In addition, the qualitative study will capture the other dimension of food waste from the viewpoint of the consumers (patients) and personnel engaged in hospital's food chain which provide deep information for understanding the actual reasons and proposing practical solutions.

The present study may encounter some limitations: Firstly, food intake will be recorded through a 24-h food recall due to the limited duration of hospitalization. While a single 24-h recall may not capture the entire intake of the patient, it can provide sufficient data to assess nutritional intake in a larger population (58). Besides, food recall is initially based on the memory that could miss some dietary data (59). Secondly, dinner food waste will not be measured due to technical issues including insufficient data collector at the time of serving of dinner. However, we will estimate food waste at dinner by subtracting the amount consumed (24-h recall) from the amount served. Finally, micronutrient status will be assessed only for two vitamins (vitamins A and D) due to limited budget. Serum 25(OH)D will be evaluated because of high prevalence of its deficiency (60) and the associated adverse clinical outcomes (61). Also, vitamin $A$ will be assessed because of its axial role in immunocompetence and possible link with malnutrition in hospitalized patients (62).

\section{Declarations}

Ethics approval and consent to participate: The project is in accordance to the ethical principles and the national standards for Medical Research in Iran. The National Ethics Committee in Biomedical Research, 
Shahid Beheshti university of medical sciences (SBMU) and NNFTRI research committee approved the study protocol and it is registered in http://ethics.research.ac.ir with the reference number SBMU.NNFTRI.REC.1398.073 (Approval Date: 2020-01-05).

Consent for publication: Results of relevant data, like medical history, dietary intake and reasons for wasting food, etc. will be published anonymous after receiving patients' consent.

Availability of data and materials: 'Not applicable'

Competing interests: 'The authors declare that they have no competing interest'

Funding: This research is funded by the Research Committee of National Nutrition and Food Technology Research Institute (NNFTRI) at Shahid Beheshti University of Medical Sciences. The funding body had no intervention in designation, collection and analysis of the study, or in interpretation of data and writing the manuscript.

Authors' contributions: TN had a substantial contribution to the whole design of the study and to the biochemical design and data analysis and will generally supervise the project. RA initially did the manuscript writing and data collection. MA significantly involved in the qualitative study's designation. DG mainly contributed to the cost calculation and analyses. BN did the statistical design and will finally analyze data. PT will mainly involve in the field work. All the authors will equally collaborate with developing approaches to diminish food waste in hospitals and with writing the article.

Acknowledgements: 'Not applicable'

\section{Abbreviations}

ABTS 3-ethylbenzothiazoline-6-sulfonate

AF activity factors

ANOVA analysis of variance

BSA body surface area

cm centimeter

ElA enzyme immunoassay

g gram

HPLC high performance liquid chromatography

hs-CRP highly sensitive $C$ reactive protein 
ICU Intensive Care Unit

IF injury factors

MNA mini-nutritional assessment

MDA malondialdehyde

NNFTRI National Nutrition and Food Technology Research Institute

NPO nil per oral

PAB pre-albumin

RMR Resting metabolic rate

SD standard deviation

SGA subjective global assessment

TAC total antioxidant capacity

TBARS thiobarbituric acid reactive substances

TEE total energy expenditure

25(OH)D 25-hydroxycalciferol

\section{References}

1. Bauer J, Bannister M, Crowhurst R, Denmeade SL, Horsley P, Mcdonald C, et al. nutritionDay: An Australian hospital's participation in international benchmarking on malnutrition. Nutrition \& Dietetics. 2011;68(2):134-9.

2. Dupertuis Y, Kossovsky M, Kyle U, Raguso C, Genton L, Pichard C. Food intake in 1707 hospitalised patients: a prospective comprehensive hospital survey. Clinical Nutrition. 2003;22(2):115-23.

3. Vesga AV, Gamboa ED. Risk of malnutrition associated with poor food intake, prolonged hospital stay and readmission in a high complexity hospital in Colombia. Nutricion hospitalaria. 2015;32(3):130814.

4. Williams P, Walton K. Plate waste in hospitals and strategies for change. e-SPEN, the European eJournal of Clinical Nutrition and Metabolism. 2011;6(6):e235-e41.

5. Agarwal E, Ferguson M, Banks M, Batterham M, Bauer J, Capra S, et al. Malnutrition and poor food intake are associated with prolonged hospital stay, frequent readmissions, and greater in-hospital mortality: results from the Nutrition Care Day Survey 2010. Clinical Nutrition. 2013;32(5):737-45. 
6. Hiesmayr M, Schindler K, Pernicka E, Schuh C, Schoeniger-Hekele A, Bauer P, et al. Decreased food intake is a risk factor for mortality in hospitalised patients: the NutritionDay survey 2006. Clinical nutrition. 2009;28(5):484-91.

7. Gout BS, Barker LA, Crowe TC. Malnutrition identification, diagnosis and dietetic referrals: are we doing a good enough job? Nutrition \& Dietetics. 2009;66(4):206-11.

8. Norman K, Pichard C, Lochs H, Pirlich M. Prognostic impact of disease-related malnutrition. Clinical nutrition. 2008;27(1):5-15.

9. Curtis LJ, Bernier P, Jeejeebhoy K, Allard J, Duerksen D, Gramlich L, et al. Costs of hospital malnutrition. Clinical Nutrition. 2017;36(5):1391-6.

10. Norouzy A, Hashemi P, Amiri A, Salehi M, Deldar K, Fakhar Y, et al. Adult malnutrition screening, prevalence in four Iranian hospitals: cross-sectional study. Mediterranean Journal of Nutrition and Metabolism. 2012;5(1):45-8.

11. Nematy M, Salami H, Norouzy A, Siadat Z, Shahsavan N, Tavallaie S, et al. Indices of malnutrition in patients admitted to general medical and chest medicine wards of an Iranian teaching hospital on admission and discharge. Mediterranean Journal of Nutrition and Metabolism.. 2013;6(1):53-7.

12. Simzari K, Vahabzadeh D, Saeidlou SN, Khoshbin S, Bektas Y. Food intake, plate waste and its association with malnutrition in hospitalized patients. Nutricion hospitalaria. 2017;34(6):1376-81.

13. Norouzy A. Nutritional status in hospitalized patients: results of national survey for nutritional assessment in Iranian hospitals. The 3rd International and 15th Iranian Nutrition Congress, Shahid Beheshti University of Medical Sciences, National Nutrition and Food Technology Research Institute, Tehran, Iran. Oct-Dec 2018; https://www.civilica.com/Paper-INC15-INC15_706.html Accessed 20 Mar 2020.

14. van Bokhorst-de van der Schueren MA, Roosemalen MM, Weijs PJ, Langius JA. High waste contributes to low food intake in hospitalized patients. Nutrition in clinical practice. 2012;27(2):27480.

15. Correia MIT, Hegazi RA, Higashiguchi T, Michel J-P, Reddy BR, Tappenden KA, et al. Evidence-based recommendations for addressing malnutrition in health care: an updated strategy from the feedM. $E$. Global Study Group. Journal of the American Medical Directors Association. 2014;15(8):544-50.

16. Lim SL, Ong KCB, Chan YH, Loke WC, Ferguson M, Daniels L. Malnutrition and its impact on cost of hospitalization, length of stay, readmission and 3-year mortality. Clinical Nutrition. 2012;31(3):345-50.

17. Correia MIT, Waitzberg DL. The impact of malnutrition on morbidity, mortality, length of hospital stay and costs evaluated through a multivariate model analysis. Clinical nutrition. 2003;22(3):235-9.

18. Gomes F, Baumgartner A, Bounoure L, Bally M, Deutz NE, Greenwald JL, et al. Association of nutritional support with clinical outcomes among medical inpatients who are malnourished or at nutritional risk: an updated systematic review and meta-analysis. JAMA network open. 2019;2(11):e1915138-e.

19. Dias-Ferreira C, Santos T, Oliveira V. Hospital food waste and environmental and economic indicators-a Portuguese case study. Waste management. 2015;46:146-54. 
20. Hong W, Kirk D. The analysis of edible plate waste results in 11 hospitals in the UK. Foodservice Research International. 1995;8(2):115-23.

21. Barton A, Beigg C, Macdonald I, Allison S. High food wastage and low nutritional intakes in hospital patients. Clinical Nutrition. 2000;19(6):445-9.

22. Taghipour $\mathrm{H}$, Mosaferi M. Characterization of medical waste from hospitals in Tabriz, Iran. Science of the total environment. 2009;407(5):1527-35.

23. Ferdowsi A, Ferdosi M, Mehrani Z, Narenjkar P. Certain hospital waste management practices in Isfahan, Iran. International journal of preventive medicine. 2012;3 Suppl 1:S176.

24. Bazrafshan E, Kord Mostafapoor F. Survey of medical waste characterization and management in Iran: a case study of Sistan and Baluchestan Province. Waste Management \& Research. 2011;29(4):442-50.

25. Monier V, Mudgal S, Escalon V, O'Connor C, Gibon T, Anderson G, et al. Preparatory study on food waste across EU 27. European Commission, Directorate-General for the Environment. 2010. http://ec. europa. eu/environment/eussd/pdf/bio_foodwaste_report.pdf; Accessed 11 Mar 2020.

26. Abeliotis K, Lasaridi K, Costarelli V, Chroni C. The implications of food waste generation on climate change: The case of Greece. Sustainable production and consumption. 2015;3:8-14.

27. Jones NE, Suurdt J, Ouelette-Kuntz H, Heyland DK. Implementation of the Canadian Clinical Practice Guidelines for Nutrition Support: a multiple case study of barriers and enablers. Nutrition in clinical practice. 2007;22(4):449-57.

28. EPA, Green Healthcare Programme. Food Waste in Irish Hospitals Factsheet. 2012. https://www.greenhealthcare.ie/wp-content/uploads/2013/04/Food-Waste-FS-FINAL.pdf. Accessed 31 May 2020.

29. Hajifathali A, Ainy E, Jafari H, Moghadam NM, Kohyar E, Hajikaram S. In-patient satisfaction and its related factors in Taleghani University Hospital, Tehran, Iran. Pakistan Journal of Medical Sciences. 2008;24(2):274.

30. Faul F, Erdfelder E, Buchner A, Lang A-G. Statistical power analyses using G* Power 3.1: Tests for correlation and regression analyses. Behavior research methods. 2009;41(4):1149-60.

31. Jarzem P, Gledhill R. Predicting height from arm measurements. Journal of pediatric orthopedics. 1993;13(6):761-5.

32. Chumlea WC, Roche AF, Mukherjee D. Nutritional assessment of the elderly through anthropometry: Ross Laboratories; 1984.

33. Chumlea WC, Guo SS, Steinbaugh ML. Prediction of stature from knee height for black and white adults and children with application to mobility-impaired or handicapped persons. Journal of the American Dietetic Association. 1994;94(12):1385-91.

34. Nikooyeh B, Shariatzadeh N, Kalayi A, Zahedirad M, Neyestani TR. Development of new predictive equations for basal metabolic rate in Iranian healthy adults: negligible effect of sex. International Journal of Vitamin and Nutrition Research. 2020 Jul 13. 
35. Mifflin MD, St Jeor ST, Hill LA, Scott BJ, Daugherty SA, Koh YO. A new predictive equation for resting energy expenditure in healthy individuals. The American journal of clinical nutrition. 1990;51(2):241-7.

36. Long $\mathrm{C}$. The energy and protein requirements of the critically ill patient. Nutritional assessment. 1984:157-81.

37. Force CMT. Subjective Global Assessment Form. 2017.

http://nutritioncareincanada.ca/sites/default/uploads/files/SGA\%20Tool\%20EN\%20BKWT_2017.pdf. Accessed 27 Oct 2019.

38. Nestle Nutrition Institute. Mini Nutritional Assessment. 1994, Revision 2009. https://www.mnaelderly.com/forms/mini/mna_mini_farsi.pdf. Accessed 12 Apr 2019.

39. Bharadwaj S, Ginoya S, Tandon P, Gohel TD, Guirguis J, Vallabh H, et al. Malnutrition: laboratory markers vs nutritional assessment. Gastroenterology report. 2016;4(4):272-80.

40. Talwar D, Ha TK, Cooney J, Brownlee C, St JO'Reilly D. A routine method for the simultaneous measurement of retinol, a-tocopherol and five carotenoids in human plasma by reverse phase HPLC. Clinica Chimica Acta. 1998;270(2):85-100.

41. Doustmohammadian A, Amini M, Esmaillzadeh A, Omidvar N, Abtahi M, Dadkhah-Piraghaj M, et al. Validity and reliability of a dish-based semi-quantitative food frequency questionnaire for assessment of energy and nutrient intake among Iranian adults. BMC research notes. 2020;13(1):1-7.

42. World Health Organization. Vitamin a deficiency and xerophthalmia: report of a joint WHO/Usaid meeting. InVitamin a deficiency and xerophthalmia: report of a joint WHO/Usaid meeting 1976.

43. Underwood BA. Methods for assessment of vitamin A status. The Journal of nutrition. 1990;120 Suppl 11:1459-63.

44. Olson JA. Vitamin A, retinoids and carotenoids. Modern nutrition in health and disease. 1994;1:287307.

45. Neyestani T, Gharavi A. Simultaneous determination of lycopene and beta-carotene with highperformance liquid chromatography. Iranian Journal of Nutrition Sciences \& Food Technology. 2007;1(3):45-50.

46. Thacher TD, Clarke BL. Vitamin D insufficiency. Mayo Clinic Proceedings. 2011; 86(1): 50-60. https://doi.org/10.4065/mcp.2010.0567

47. Kei S. Serum lipid peroxide in cerebrovascular disorders determined by a new colorimetric method. Clinica chimica acta. 1978;90(1):37-43.

48. Neyestani T, Shariatzadeh N, Gharavi A, Kalayi A, Khalaji N. Physiological dose of lycopene suppressed oxidative stress and enhanced serum levels of immunoglobulin $M$ in patients with Type 2 diabetes mellitus: a possible role in the prevention of long-term complications. Journal of endocrinological investigation. 2007;30(10):833-8.

49. Neyestani TR, Fereydouni Z, Hejazi S, Salehi-Nasab F, Nateghifard F, Maddah M, et al. Vitamin C status in Iranian children with acute lymphoblastic leukemia: evidence for increased utilization. Journal of pediatric gastroenterology and nutrition. 2007;45(1):141-4. 
50. Nehring SM, Patel BC. C Reactive Protein (CRP). InStatPearls [Internet] StatPearls Publishing. 2019. https://www.ncbi.nlm.nih.gov/books/NBK441843/ Accessed 10 May 2020

51. Busher J. Serum Albumin and Globulin. In: Walker H, Hall W, Hurst J, editors. Clinical Methods: The History, Physical, and Laboratory Examinations. Boston: Butterworths; 1990. https://www.ncbi.nlm.nih.gov/books/NBK204/

52. Kuszajewski M, Clontz A. Prealbumin is best for nutritional monitoring. Nursing2020. 2005;35(5):70-1.

53. Long $\mathrm{T}$, Johnson M. Rigour, reliability and validity in qualitative research. Clinical effectiveness in nursing. 2000;4(1):30-7.

54. Vaismoradi M, Turunen $\mathrm{H}$, Bondas T. Content analysis and thematic analysis: Implications for conducting a qualitative descriptive study. Nursing \& health sciences. 2013;15(3):398-405.

55. Grass F, Bertrand P, Schäfer M, Ballabeni P, Cerantola Y, Demartines N, et al. Compliance with preoperative oral nutritional supplements in patients at nutritional risk only a question of will? European journal of clinical nutrition. 2015;69(4):525.

56. Mahan LK, Raymond JL. Clinical: Biochemical, Physical, and Functional Assessment. Krause's food \& the nutrition care process. 14th ed. Elsevier; 2017. p. 107.

57. Benjamin DR. Laboratory tests and nutritional assessment: Protein-energy status. Pediatric Clinics of North America. 1989;36(1):139-61.

58. Biro G, Hulshof K, Ovesen L, Cruz JA. Selection of methodology to assess food intake. European journal of clinical nutrition. 2002;56(2):S25-S32.

59. Block G. A review of validations of dietary assessment methods. American journal of epidemiology. 1982;115(4):492-505.

60. Nikooyeh B, Abdollahi Z, Hajifaraji M, Alavi-majd H, Salehi F, Yarparvar AH, et al. Vitamin D status and cardiometabolic risk factors across latitudinal gradient in Iranian adults: National food and nutrition surveillance. Nutrition and health. 2017;23(2):87-94.

61. Botros RM, AbdElsalam Besibes MM, Bahaaeldin AM, Abo Elyazed S. Vitamin d status in hospitalized chronically ill patients. Journal of the American College of Nutrition. 2018;37(7):578-82.

62. Huang Z, Liu Y, Qi G, Brand D, Zheng SG. Role of vitamin A in the immune system. Journal of clinical medicine. 2018;7(9):258.

\section{Tables}

Table 1- RMR estimation(kcal/d) 
Iranians equation ${ }^{(34)}$

Males (18-30 yrs): $(8.4 \times \mathrm{Ht}$ in $\mathrm{cm})+(5 \times \mathrm{wt}$ in $\mathrm{kg})+(27.5 \times$ age in yrs) -869.7

Males (31-60 yrs): (7.8x Ht in cm) + (12.5× wt in kg) (5.64x age in yrs) -349.9
Mifflin equation ${ }^{(35)}$

Males ( $\geq 60$ years): $10(\mathrm{wt})+6.25(\mathrm{Ht})-$ 5 (age) +5

Females ( $\geq 60$ years): 10 (wt) +6.25

$(\mathrm{Ht})$ - 5 (age) - 161

Females (18-30 yrs): $(8.4 \times \mathrm{Ht}$ in $\mathrm{cm})+(5 \times \mathrm{wt}$ in $\mathrm{kg})+$ (27.5x age in yrs) -979.7

Females (31-60 yrs): $(7.8 \times \mathrm{Ht}$ in $\mathrm{cm})+(12.5 \times \mathrm{wt}$ in $\mathrm{kg})$ $(5.64 \times$ age in yrs $)-455.4$

*age: age in years; $d$ : day; Ht. Height in centimeters; $R M R$ : Resting metabolic rate; wt. actual body weight in kilograms; yrs. years

Table 2-Injury and activity factors ${ }^{(36)}$

\begin{tabular}{|c|c|c|c|}
\hline Condition & IF & Condition & AF \\
\hline Minor surgery & $1.0-1.1$ & Confined to bed & 1.2 \\
\hline Major surgery & $1.1-1.3$ & Ambulatory , low activity & 1.3 \\
\hline Mild infection & $1.0-1.2$ & Average activity & $1.5-1.75$ \\
\hline Moderate infection & $1.2-1.4$ & Highly active & 2.0 \\
\hline Severe infection & $1.4-1.8$ & & \\
\hline Skeletal or blunt trauma & $1.2-1.4$ & & \\
\hline Skeletal or head trauma (steroid treated) & $1.6-1.8$ & & \\
\hline Burns involving $\leq 20 \%$ BSA & $1.2-1.5$ & & \\
\hline Burns involving $20-40 \%$ BSA & $1.5-1.8$ & & \\
\hline Burns involving $>40 \%$ BSA & $1.8-2.0$ & & \\
\hline
\end{tabular}

$A F$ : activity factor; $B S A$ : body surface area; IF: Injury factor Table 3-Topic Guides for the different target groups 


\section{Participants' Question \\ subgroup \\ (interviewee)}

Nurses

1. What is your opinion about the quality of served foods/ snacks for patients in this hospital?

2. What is your opinion about the quantity of served foods/ snacks for patients in this hospital?

3. In your opinion which parts of the foods have not been eaten (meat/chicken/fish, bread, rice, vegetables, dairy, fruits) by patients in this hospital? And why?

4. Do you think to which extent the hospital's food is in accordance with patients' requirements and conditions? Please clarify.

5. In your opinion, for what reasons incomplete consumption of foods by patients exists?

6. What is your recommendation for the patients to completely consume their foods?

Nutritionists

1. What is your opinion about the quality and quantity of served foods/ snacks for patients in this hospital?

2. In your opinion which parts of the foods have not been eaten

(meat/chicken/fish, bread, rice, vegetables, dairy, fruits) by patients in this hospital? And why?

3. In your opinion, which factors are more important to the patients about the hospital's food?

4. What is your recommendation for the promotion of hospital's food quality?

5. What is your recommendation for decreasing hospital's food wastes and increasing patients' food intake in this hospital?

Food providers
1. Do you think which factors could affect the quality and quantity of hospital's food in this hospital?

2. In your opinion, which factors are of more importance for patients or they are paying more attention to in this hospital?

3. From your viewpoint, why do not some patients eat their entire food or do not eat hospital's food at all in this hospital?

4. From your viewpoint, which obstacles do exist to promote hospital's food quality in this hospital?

5. what do you suggest to reduce the food wasted by patients or in hospital's kitchen in this hospital?

Patients

1. Do you consume all of the hospital's food? If not, why?

2. What is your opinion about the quality of served foods/ snacks for patients in this hospital? 
3. What is your opinion about the quantity of served foods/ snacks for patients in this hospital?

4. What is the most important factor in hospital's food for you? (e.g. taste, appearance, texture, etc.)

5. In your opinion, which effects have the quantity and type of food served by hospital on your disease? (Is hospital's food in accordance with your disease?

6. Do you think what should would we do to improve the quality of the hospital's food (and to decrease food waste)?

\section{Hospital managers}

1. What is your opinion about the quality of hospital's food in this hospital?

2. What is your opinion about the quantity of hospital's food in this hospital?

3. In your opinion, which items should be considered about the type, serving method, and totally the quality of patient's food in this hospital?

4. What is your recommendation for decreasing the hospital's food waste and improve the patient's food intake in this hospital? (do you think how we can decline the amount of wasted food? Please clarify.)

5. From your viewpoint, which obstacles exist to promote the quality of hospital's food?

Food staff (preparing and serving staff)
1. Do you think the amount of served foods is enough for patients?

2. In your idea, which factors can improve the quality of patients' food in this hospital?

3. Which items in food are more important to the patients in this hospital? (taste, texture, temperature, etc.)

4. How can we reduce the amount of food wastes by the patients in this hospital?

\section{Figures}


Patient hospitalized in medical and surgical wards of 3 general hospitals

Inclusion of patients having inclusion criteria and without exclusion criteria $(n=171)$

Collection of demographic and anthropometric data

Measurement of quantity and cost of plate food waste during a day

Collection of food intake (a 24-h recall) and nutritional requirement of patients and nutritional value of food waste

Assessment of subjective malnutrition (using SGA and MNA tools)

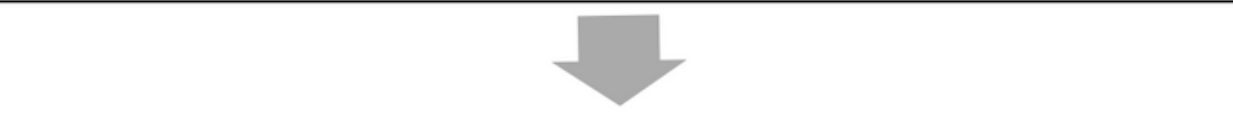

Assessment of protein and micronutrient malnutrition using biochemical tests (retinol and calcidiol) and antioxidant biomarkers

Qualitative study to determine causes of food waste by patients

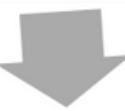

Data analysis and comparison among wards and hospitals

Figure 1

A summary of the steps that will be taken to fulfill the study aims 